\title{
Women with Diabetes-Two Specifications Mean Double Trouble
}

\author{
Sana Ajmal, ${ }^{1,2}$ Anum Anwar, ${ }^{1,3}$ and Annum Khan ${ }^{1,2}$ \\ 1. Meethi Zindagi, Rawalpindi, Pakistan; 2. National University of Sciences and Technology, Pakistan; 3. Dr Panjwani Center for Molecular Medicine
} and Drug Research (PCMD), International Center for Chemical and Biological Sciences (ICCBS), University of Karachi, Karachi, Pakistan

G ender inequality is a highly discussed and topical issue throughout the world at present. Women in developing countries are particularly vulnerable to gender discrimination, especially women living with chronic illness. This commentary piece discusses the discriminaton issues faced by women with type 1 diabetes in the developing world as they try to conform to the gender roles expected of them whilst managing their diabetes, and changes that could be made in the future.

\section{Keywords}

Diabetes, discrimination, gender inequality, gender roles, women with diabetes, developing world

Disclosures: Sana Ajmal, Anum Anwar, and Annum Khan have nothing to disclose in relation to this article. Review Process: This is a commentary article and as such did not undergo the journal's usual peer review process.

Authorship: All named authors meet the International Committee of Medical Journal Editors (ICMJE) criteria for authorship of this manuscript, take responsibility for the integrity of the work as a whole, and have given final approval to the version to be published.

open Access: This article is published under the creative Commons Attribution Noncommercial License, which permits any noncommercial use, distribution, adaptation, and reproduction provided the original author(s) and source are given appropriate credit. (C) The Author(s) 2018

\section{Received: May 4, 2018}

Published Online: May 22, 2018

Citation: US Endocrinology, 2018;14(1):32-34

Corresponding Author: Sana Ajmal, 176, Lane 7, Askari 10, Near Chaklala Scheme 3, 46000, Rawalpindi, Pakistan. E: sanaajmal@meethizindagi.org

Support: No funding was received in

the publication of this article.
Diabetes, with its ever growing prevalence, becomes a two-front struggle for young females living with it in developing countries. Firstly, they are already subjected to discrimination and social pressures because of the gender they were born with. Furthermore, thanks to the inconsiderate prevention messages, awareness campaigns about diabetes-related complications, judgmental attitudes of healthcare professionals, and plenty of bad management examples, diabetes is a constant source of discrimination for women living with it in the developing world - being a woman and having diabetes means double trouble!

There are certain stereotypes that women have to face throughout their lifetime. Within certain cultures there are roles a woman is expected to fit into, such as looking after household work, bearing and raising children, and looking a certain way. All of these gendered roles are continuous (all day, every day of the year) and require a lot of time.

It is pertinent to mention here that men also have to live with stereotype roles attached to their gender, and therefore have different issues to contend with. Women, however, who have traditionally been seen as the weaker gender and being more controlled by the opinions and decisions of the male leadership, be it with family, organization, or society in general, have lesser chances of rising above their circumstances and bringing about a positive change in their lives.

As various reports on the issue state, ${ }^{1-4}$ the two most important stereotypes creating gender inequality are: a boy is economically more useful than a girl; and a girl is for getting married and raising a family. This means that if a choice has to be made between sending a boy or a girl to school, the boy will be given precedence. This also means that boys usually receive more and better quality food than girls, and that girls without family stability are vulnerable to exploitation. Amongst this vulnerable group of girls, 1 in 10 lives with diabetes.

Statistics in the International Diabetes Federation (IDF) Atlas $2017^{5}$ show that the mean annual healthcare expenditure per person with diabetes is high, even in countries with a majority of population living below poverty line, such as Congo, India, Bangladesh, Pakistan, and many others. Some data collected by T1international ${ }^{6}$ shows that in India, insulin and supplies for managing type 1 diabetes cost USD 1,342 annually, whereas the average annual income is only USD 1,693. Similarly, in Pakistan, estimates made on basal bolus regimen and twice-a-day testing show that insulin and supplies cost USD 1,356 annually whereas the average annual income is USD 1,629, which is approximately $83 \%$ of the average total annual income! Recent surveys, however, indicate a much lesser income percentage, based on the data collected. However, it is very apparent that most people in Pakistan still use pre-mixed or short/intermediate acting insulins as there are no records collected for rapid acting and long acting insulins. 6,8 
"I was raised with the belief I belong to a weaker gender; and the addition of diabetes to that signs me up for a compromising future. Like every other Asian parent, my mother started looking for a match for me as I got into my twenties. I realized that she too had come under the pressure that the society had put on her" Aisha Bano (name changed to protect identity), Pakistan.

"I was involved with a guy. He came to learn that I was diabetic and told me that diabetes had a cure. So I should try and get the cure. He ended the relationship because I said there was no cure. I then dated another guy for about a year. Everything was moving on smoothly, but all of a sudden, he told me that the mother says she doesn't want someone with diabetes in the family. So he ended the relationship without doing anything about it", Theresa, Ghana.

"Some time back, a friend of mine proposed me. He wanted to marry me and knew that I had diabetes. He did not have any issues with that. I wanted to marry him too. In this regard, his sister came to meet me. She knew that I had diabetes. She tried to make me see my 'short-comings'... she told me that because of diabetes, I may not be able to look after their household in a good way, I may not be able to carry forward their family's generation. She wasn't ready to believe me that I could manage myself well. This is how I was rejected in the very first meeting", Annum Khan (co-author), Pakistan.

"People often ask me, 'You are so sick! Who will marry you?' or 'Will you have a baby? Abnormal?'”, Fatimath Juzan Mohamed, Maldives.

"Amongst other issues, one of the reasons for breaking my engagement of 3 years was the beeping of my insulin pump, and the fear that the guy would spend a large portion of his earning on my health. A woman is, many-a-times, not allowed to work for sustaining herself. After this, my family restricted me from disclosing about diabetes to any new marriage proposal. Hiding it was a suffocating experience. Having lived with it for this long, it was like a part of me. The feeling of helplessness crushed my self-esteem badly," Aisha Bano (name changed to protect identity), Pakistan.

"As a woman with diabetes, I am neither allowed to work and earn for sustaining myself (which is part of the culture), nor am I considered fit enough to do the household work. Hence I haven't been able to find a life partner," Priya Mathur (name changed to protect identity), India.

"After diagnosis the thing that I had to fight the most was social acceptance. I was not supposed to tell anyone that I have diabetes and this pressure was put on me by my family, which was very painful. I have to live with a medical condition, I have to take my insulin, but I wasn't allowed to tell anyone about my condition", Annum Khan (co-author), Pakistan.

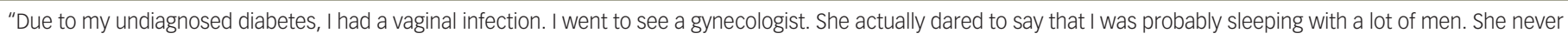
thought of any other possibility. She had no 'creativity' to conduct any blood test and see if there could be other reasons behind the infection", Sofia, Costa Rica.

"My diabetes type 1 was diagnosed after I got married. My in-laws did not allow me to tell this to anyone, so I would need to accept sugary drinks when we were visiting people, as I could neither refuse, nor tell the truth", Maira Shafiq (name changed to protect identity), Pakistan.

"During my second pregnancy, I was facing a slight issue and went to see my gynecologist. She was on leave that day and I was referred to another, more senior gynecologist who was with a group of students at the time walked into her office with my mother, who is herself a doctor. As we explained the issue I was facing, she started telling us that we were stupid to let me conceive in the first place. Then she made fun of my mother saying the despite being a doctor, she didn't know what is not right for me, and first got me married off, and then didn't guide me about why not to conceive. This was such a shock for both my mom and me that we walked out of her office. This is how they create misconceptions which later on lead to discrimination. I have two healthy boys today", Sana Ajmal, Pakistan.

In a culture where, without any viable economic benefit of spending on a young girl or woman with diabetes, the cost of a female child having diabetes can be seen as an additional burden on the family, while the available healthcare is insufficient, inadequate, and expensive. Diabetes education is also often unavailable. All these issues make it difficult for a young woman with diabetes to properly treat and manage her diabetes, creating many examples of bad health outcomes. These examples of poor health outcomes reinforce stereotypes, i.e., what good is a girl if she is not healthy enough to get married and raise a family? The quality of a woman is often seen to be lowered by the presence of diabetes, ${ }^{9}$ similar to how the quality of fruit is lowered if it gets a disease.

Aside from the expense, diabetes management takes a lot of time, as does the gendered role expected from a woman, and as such, how well each or both of these tasks is performed is likely to be affected. This means that a woman with diabetes is either unable to completely manage the expectations around her role as a woman or is unable to manage her health properly, which in term is likely to interfere with her role as a woman.

People in the developing world often raise their daughters with the sole purpose of marrying them off to eligible bachelors and raising families. For a woman who already has to meet these high expectations, she may inevitably find it hard to manage her health too. This interferes with her role of becoming a mother and taking care of the daily needs of a family, hence the understanding that "women with diabetes cannot have healthy children and they cannot take care of families". But what is important here is the root cause of the mess - the high gendered expectations.

The consequences of the economic and social problems highlighted above are that many men and their families do not want to have a relationship with "diabetes-infested" young women. Often they do not have enough economic resources available to support a "damaged" life partner, and there is little social acceptance. There are many examples of young women who have lost their husbands due to the effects of diabetes during intimate relations. If a woman is married off by the family with their diabetes diagnosis being kept hidden, it is common for them to divorce once the husband finds out.

Meethi Zindagi is a community organization in Pakistan that aims to create awareness, encourage empowerment and educate people living with diabetes, advocating for their rights and supporting them medically as well as psychologically through the underlying principle of peer-support. Meethi Zindagi is also partnered with some international organizations (such as The Access Alliance, League of DiAthletes), advocating for people living with diabetes (for more information about Meethi Zindagi, please visit www. meethizindagi.org). As part of the study conducted by Meethi Zindagi in 
2017, and presented at the IDF World Diabetes Congress 2017, we aimed to identify the various challenges faced by young women with diabetes due to discrimination..$^{10} \mathrm{~A}$ number of participants from various developing countries were asked to share their stories. They were asked about how it is to live with two specifications in a patriarchal society: the specification of being a woman and the specification of having diabetes. Some of them are included in Table 1, with some of the identities hidden for anonymity.

Discrimination in the name of diabetes doesn't stop here. It is even present amongst healthcare professionals themselves. For instance, it is a common belief in the developing world, even amongst a large number of gynecologists, that women with diabetes cannot have children.

In the developing world, many gynecologists are not confident to handle a type 1 pregnancy and refuse to take on such patients. If they do agree to treat a pregnant woman with type 1 diabetes often they do not allow the pregnant woman to go into normal labor. Also, managing blood sugar levels during pregnancy, which requires expert guidance, is often left completely to the pregnant woman with diabetes to manage. The concept of a team of healthcare experts managing a pregnant patient with type 1 diabetes is not widespread and as a result the management is left to the mother-to-be and her medical specialist, who may not be experienced in managing diabetes during pregnancy, and therefore unaware of the hormonal level changes that lead to swinging blood sugar levels.

A lot of work needs to be done towards combatting discrimination. Advocating for women with diabetes is the simplest and perhaps the most effective solution in the medium to long-term. Creating role models and showing the real faces of women with diabetes, who are successful in their gendered roles, or in professional roles, or have had successful pregnancies and healthy children, to the society at large could help clear many misconceptions. Apart from this, training for gynecologists to equip them with the knowledge and tools for handling pregnancies of women with diabetes is a must-address area. Most importantly, diabetes prevention campaigns that aim to scare the public by highlighting the effects of complications should be revisited. These campaigns are a big source of cementing the negative image around diabetes in the head of everyone, leading to negativity and discrimination. While prevention is a possibility and should be highlighted, the positive image of a good life with well-managed diabetes will help those who cannot prevent diabetes, experience positivity around themselves.
1. World Economic Forum. The global gender gap report 2017. Available at: www3.weforum.org/docs/WEF_GGGR_2017.pdf (accessed: May 21, 2018).

2. UNESCO Report on gender inequality in education. Why gender equality in basic education in pakistan? (2010). Available at: unesdoc.unesco.org/images/0021/002151/215106e.pdf (accessed: May 21, 2018)

3. UNESCO Report by the United Nations Educational, Scientific and Cultural Organization. World atlas of gender equality in education (2012). Available at: www.unesco.org/new/fileadmin/ MULTIMEDIA/HQ/ED/pdf/Atlas-education-gender-equality1.pdf (accessed: May 21, 2018)
4. McCleary-Sills J, Hanmer L, Parsons J, Klugman J. Child marriage: A critical barrier to girls' schooling and gender equality in education. The Review of Faith \& International Affairs. 2015;13:69-80.

5. IDF Atlas 2017. International Diabetes Association. Avaialbale at: www.diabetesatlas.org/resources/2017-atlas.html (accessed May 17. 2018)

6. T1international. Access to insulin and supplies survey. Available at: www.t1international.com/insulin-and-supply-survey (accessed: May 21, 2018).

7. Government of Pakistan Ministry of Finance. Economic indicators report 2018. Available at: www.finance.gov.pk/survey/chapters 18/ Economic_Indicators_2018.pdf (accessed: May 21, 2018).
8. Ogle GD, Kim H, Middlehurst AC, Silink M, Jenkins AJ. Financial costs for families of children with Type 1 diabetes in lowerincome countries. Diabetic Med. 2016;33:820-6.

9. Shaheera T. In the eyes of my family, I'm damaged goods here's why. the Tempest. Available at: https://thetempest. co/2017/10/13/culture-taste/ive-never-done-anything-immoralbut-im-a-damaged-good (accessed May 17, 2018).

10. Ajmal S. Diabetes and Stigma - perspective of young women of the developing world. World Diabetes Congress 2017, 4-8 December, Abu Dhabi. Presentation no. 155.



Sana Ajmal was diagnosed with type 1 diabetes at the age of 15 and has been living with it for over 19 years. Having a passion for diabetes advocacy, she joined IDF's Young Leaders in Diabetes Programme in 2011 and served as the Vice President and the President-Elect. She is the Founder and Executive Director of Meethi Zindagi, an organization working to promote awareness, education and psycho-social needs of the diabetes community. Meethi Zindagi advocates for comprehensive people-centered care. Sana is a mother of two boys, and also teaches in an engineering university in Pakistan. Living in a semi-conservative culture, and working with local and international diabetes community, she has in-depth knowledge of how diabetes-related stigma affects the lives of young women of the developing world.

Anum Anwar currently serves as Director of Advocacy at Meethi Zindagi, which focuses on changing the mindsets and improving behavior of society towards people with diabetes (PWD). Her key focus is social discrimination in diabetes and she is a certified Diabetes Educator. Dr Anwar often speaks publically for Meethi Zindagi to educate people with her own experiences and is continuously building on the team of patient advocates in the type 1 diabetes community. Aside from her passion for diabetes advocacy, Dr Anwar is a research fellow at Dr Panjwani Center for Molecular Medicine and Drug Research (PCMD), International Center for Chemical and Biological Sciences (ICCBS) University of Karachi where some of her research is focused around diabetes.

Annum Khan is a highly skilled and dedicated mental health professional with a decade of experience and demonstrated success in providing exceptional care and implementing effective treatment plans for patients with varying mental health disorders, specializing in autism as a PhD Scholar. She has been associated with the Center for Counseling and Career Advisory (C3A), National University of Sciences and Technology (NUST), Islamabad, Pakistan for more than 6 years. She has received numerous certifications including hypnotherapy (US), cognitive behavioral therapy (Canada), and eidetic therapy (UK). She joined Meethi Zindagi in 2016, and is currently serving as Director of Programs. After her onset of diabetes, she decided to work on the psychological wellbeing of patients with diabetes. Since then she has provided free outpatient services to patients with diabetes. 